\title{
Sural nerve and short saphenous vein entrapment-a case report
}

\section{Satheesha Nayak B.}

Department of Anatomy, Melaka Manipal Medical College (Manipal Campus), International Centre for Health Sciences, Manipal576104, Karnataka, India

Address for correspondence: Dr. Satheesha Nayak, Associate Professor, Department of Anatomy, Melaka Manipal Medical College (Manipal Campus), International Centre for Health Sciences, Manipal-576104, Karnataka, India. E-mail: nayaksathish@yahoo.com

\section{ABSTRACT}

Although the sural nerve is the most extensively studied nerve in man, there is a dearth of data regarding the normal variations in the size and distribution of axons in normal subjects. Since the sural nerve is the most frequently used sensory nerve in nerve transplantation, knowledge of variations in its course and distribution plays an important role in the surgical procedures. Here, an entrapment of the sural nerve in the gastrocnemius is reported. The short saphenous vein also passed through the gastrocnemius muscle along with the sural nerve.

\section{KEY WORDS}

Sural nerve, Entrapment, Short saphenous vein

\section{INTRODUCTION}

he sural nerve is a branch of the tibial nerve. It is given off in the popliteal fossa. It normally descends between the two heads of the gastrocnemius and then descends down lateral to the tendocalcaneus to a region between calcaneus and lateral malleolus. It is accompanied by the short saphenous vein in most of its course. It supplies the skin of the posterolateral part of the lower third of the leg and the lateral border of the foot. 


\section{CASE REPORT}

During the routine dissections for the medical undergraduates, a variation in the course of the sural nerve and the short saphenous vein was noted. In the current case, the sural nerve pierced the gastrocnemius muscle along with the short saphenous vein instead of passing superficial to it [Figure 1]. The short saphenous vein, below the level of entrapment was dilated. The upper, terminal part of short saphenous vein was extremely thin [Figure 1]. This variation was found in the left leg of a male cadaver aged approximately 50 years and was unilateral.

\section{DISCUSSION}

This variation found here is of clinical and surgical importance since sural nerve is the most frequently used sensory nerve in nerve transplantations. It is either transplanted alone or together with the other elements of the neurovascular stalk within the superficial sural flap. Clinically, the sural nerve is widely used for both diagnostic (biopsy and nerve conduction velocity studies) and therapeutic purposes (nerve grafting). Thus, a detailed knowledge of the anatomy of the sural nerve and its contributing nerves are important in carrying out these and other procedures. Though the sural nerve is considered to be a sensory nerve, motor fibres have been found in $4.5 \%$ of nerves. ${ }^{1}$ In the current case, since the nerve passed through the gastrocnemius muscle, it is likely that it gave motor branches to the muscle as it passed through it. Presence of motor fibres may play important role in sural nerve biopsy and pathological findings. This abnormal course of the sural nerve can produce pain up on the contraction of the gastocnemius or altered sensation over the area of its distribution. Pain associated with sural nerve entrapment in athletes ${ }^{2}$ and in scar tissue after the injury of gastrocnemius ${ }^{3}$ has already been reported. In the former case, the sural nerve was entrapped in the superficial sural aponeurosis. In the case reported here, the nerve passed through the fleshy part of gastrocnemius.

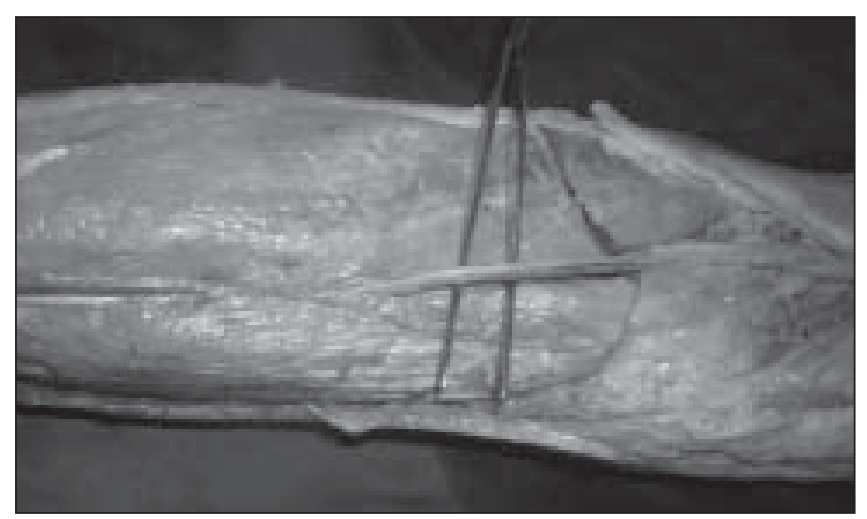

Figure 1: Superficial dissection of the back of the leg showing sural nerve and short saphenous vein entrapped in the gastrocnemius

The enlargement of the short saphenous vein in this case could be due to the obstruction for its blood flow by the contracting gastrocnemius muscle. The deep veins of the legs are in an advantageous position for venous drainage as the drainage is favored by the contraction of the neighbouring muscles. But in a case like this, where a vein is passing through the muscle, the sustained pressure on the vein might be a factor hindering the blood flow. That could be the possible reason for the enlargement of the vein below the entrapment. If not, the vein should have enlarged in its proximal part as well. The entrapment of the short saphenous vein has not been reported yet.

The knowledge of this kind of entrapment of sural nerve and short saphenous vein is very important for plastic surgeons, sport medicine, physiotherapy, clinical and surgical procedures.

\section{REFERENCES}

1. Amoiridis G, Schols L, Ameridis N, Przuntek H. Motor fibers in the sural nerve of humans. Neurology 1997;49:1725-8.

2. Fabre T, Montero C, Gaujard E, Gervais-Dellion F, Durandeau A. Chronic calf pain in athletes due to sural nerve entrapment. $A$ report of 18 cases. Am J Sports Med 2000;28:679-82.

3. Bryan BM 3rd, Lutz GE, O'Brien SJ. Sural nerve entrapment after injury to the gastrocnemius: a case report. Arch Phys Med Rehabil. 1999;80:604-6. 